\title{
Bacterial Endophyte Inhabiting Durio zibethinus and its Radical Scavenging and Antidiabetic Potential
}

\author{
Sridevi Chigurupati ${ }^{1, *}$, Shantini Vijayabalan ${ }^{2}$, Vasanth Raj Palanimuthu ${ }^{3}$, Suprava Das ${ }^{4}$, \\ Saurabh Bhatia ${ }^{5,6}$ \\ 1'Department of Medicinal Chemistry and Pharmacognosy, College of Pharmacy, Qassim University, Buraidah, SAUDI ARABIA. \\ ${ }^{2}$ School of Pharmacy, Faculty of Health and Medical Sciences, Taylor's University, Subang Jaya, Kuala Lumpur, MALAYSIA. \\ ${ }^{3}$ Department of Pharmaceutical Biotechnology, JSS College of Pharmacy, JSS Academy of Higher Education \& Research, Ooty, \\ Nilgiris, Tamil Nadu, INDIA. \\ ${ }^{4}$ Department of Pharmacology, Faculty of Medicine, AIMST University, Semeling, 08100 Bedong, Kedah, MALAYSIA. \\ ${ }^{5}$ Natural \& Medical Sciences Research Center, University of Nizwa, P.O. Box 33, 616 Birkat Al Mauz, Nizwa, OMAN. \\ ${ }^{6}$ Amity Institute of Pharmacy, Amity University ,Gurgaon, Haryana, INDIA.
}

\begin{abstract}
Background: Endophytes, markedly receiving interest and has been detected to be remarkable sources of bioactive metabolites. Endophytes, which are also called as endosymbionts have pulled into consideration in the discovery for novel bioactive compounds that can be utilized as new medications. In the current study, endophyte has been isolated from Durio zibethinus leaves. 16s rRNA partial genome sequencing was used to identify selected endophyte and the obtained bacterial endophytic crude extract (DZLM) was subjected for the antioxidant and antidiabetic investigations. Results: Cronobacter sakazakii was identifies as the endophye. Qualitative phytochemical test on DZLM confirmed the presence of phenols, carbohydrates, alkaloids, flavonoids, steroids, mucilage, and glycosides. The antioxidant assay of DZLM showed the good antioxidant potency with $\mathrm{IC}_{50} \pm$ SEM: $161 \pm 0.08 \mu \mathrm{g} / \mathrm{mL}$ for DPPH assay and $\mathrm{IC}_{50} \pm \mathrm{SEM}$ : $126 \pm 0.09 \mu \mathrm{g} / \mathrm{mL}$ for ABTS assay. Antidiabetic assay results demonstrated a dosedependent percentage inhibition of the enzymes. The results revealed good inhibition of $\alpha$-amylase with $\mathrm{IC}_{50} \pm$ SEM: $239 \pm 0.08 \mu \mathrm{g} / \mathrm{mL}$ and $\alpha$-glucosidase inhibition with $\mathrm{IC}_{50} \pm \mathrm{SEM}$ : $241 \pm 0.08 \mu \mathrm{g} / \mathrm{mL}$ for DZLM compared to the standard drug, acarbose. Conclusion: The study uncovered the fact that DZLM has a wellspring of natural source of antioxidant and antidiabetic agents and further studies are required for fractionation of the active constituents existing in DZLM and also their structural elucidation which supports the application of endo-symbionts as the basis of future natural medicines.
\end{abstract}

Key words: Cronobacter sakazakii, Durio zibethinus, Endophytes, $\alpha$-amylase, $\alpha$-glucosidase.

\section{INTRODUCTION}

Endophytes are significant mutual symbiont inhabitants present in the host plant's tissues with no harmful impacts. Endophytes can be distinguished as bacteria, actinomycetes or fungi. Because of the long hostparasitic relationship, endophytes able to produce secondary metabolites like that of plants. They are wellspring of secondary metabolites, for instance, anticancer, antidiabetic, antifungal and antibacterial activity. ${ }^{1}$ From a practical perspective, drug production by endophytes fermentation will provide more benefit since it will be quick, reproducible and boundless and climate/ season independent. The disclosure of endophytes with the capacity to produce precisely the same active compound produced by their host prompts another approach in active compound generation from natural product economically. ${ }^{1,2}$ Production of compounds can be enhanced by endophytes for bearing demands while keeping the ecosystem and biodiversity sustainable. Endophytes have pulled into
Submission Date: 30-09-2020; Revision Date: 18-03-2021: Accepted Date: 08-07-2021

DOI: 10.5530/ijper.55.3.159 Correspondence:

Dr. Sridevi Chigurupati Department of Medicinal Chemistry and Pharmacognosy, College of Pharmacy, Qassim University, Buraidah, Saudi Arabia, SAUDI ARABIA. Phone: +966-597302849 Email id: sridevi.phd@gmail. com

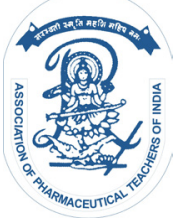

www.ijper.org 
consideration in the discovery for novel bioactive compounds that can be utilized as new medications supplanting those against which pathogenic strains have quickly obtained resistance. ${ }^{3}$

Diabetes mellitus is known as a metabolic disorder which happens because of impeded glucose regulation or weakened carbohydrate hydrolyzing enzymes. The medications conventionally use synthetic drugs all through their lifetime. Not with standing, extended haul treatment had adverse effects, for example, oedema with gastrointestinal disorders and hyponatremia. ${ }^{4}$ The result is the inclination of today's society to favour traditional medications due to their affordability, eco-friendly nature and significantly fewer side effects. ${ }^{5}$ There are unsettling impacts in antioxidant defense frameworks in diabetes mellitus. ${ }^{6}$ As diabetic intricacies can be treated with antioxidants. ${ }^{7}$ The commence of the "unifying theory" that hyperglycaemia-prompted oxidative stress could relate to the pathogenesis of each complexity. ${ }^{8}$

Durio zibethinus commonly referred to as Durian in Southeast Asia and considered as "king of fruits". It was been reported to contain bioactive compounds such as phenols, carotenoids, anthocyanins and flavonoids., ${ }^{910}$ Traditionally, various parts of $D$. zibethinus have been used for various therapeutic purposes and many scientific studies on this plant were reported. The secondary metabolites produced by endophyte inhabiting $D$. zibethinus and their antioxidant and antidiabetic potentials are not been investigated so far. The current study is mainly focused on endophytes from Durian leaves and screening the antioxidant and antidiabetic potential of secondary metabolites of crude fractions of endophyte.

\section{MATERIALS AND METHODS}

\section{Sample collection}

Leaves of $D$. zibethinus had been accumulated from Baling town, Kedah, Malaysia and authenticated by AIMST University, Pharmacognosy section, Malaysia (Voucher specimen No. AIMST/FOP/08). For sampling, matured and healthy plants were chosen, processed within the next few hr. to produce endophytic bacterial communities.

\section{Isolation of endophytic bacteria}

The isolation of endophytes was made in accordance with the method described with minor modifications. ${ }^{11,12}$ After thorough washing with water, the plant materials were subjected to surface sterilization with $70 \%$ ethanol, followed by soaking in ethanol (95\%) and in sodium hypochlorite $(5 \%)$ solution. Successively, the segments washed repeatedly using sterile distilled water. Then the leaves were eventually cut off to 0.5 to $1 \mathrm{~cm}$ in length and 3 to $4 \mathrm{~mm}$ in diameter. In each of the nutrient agar plates, leaf segments were arranged, and agar plates were allowed for incubation for $24 \mathrm{hr}$. to $36 \mathrm{hr}$. (room temperature) till the growth of bacteria is observed.

\section{S rRNA partial gene sequencing}

The forward primer (Bakll W-F 5'- AGT TTG ATC MTG GCT CAG-3') and reverse primer (Bak-R 5'GGA CTA CHA GGG GGG TAT CTA AT -3') have been used for the PCR amplification of 16S rRNA partial gene sequencing for identified endophyte strains. Thermocycler is used for the PCR amplification with the specified conditions. ${ }^{12}$ To identify the sequence similarity, the DNA data has been BLAST analyzed using NCBI database.

\section{Bacterial endophytic crude extraction}

On nutrient agar petri plate, the isolated endophyte was grown under aerobic conditions for $24 \mathrm{hr}$. The subculture introduced into the nutrient broth, incubated at $37^{\circ} \mathrm{C}$ for 3 to 4 days on a shaker (110 Rpm). After fermentation, brine solution and ethyl acetate solvent were added into the culture broth, with the ratio of $1: 3$ and was subjected to extraction. The organic phase has been filtered, anhydrous sodium sulphate was used for drying and then ethyl acetate was evaporated. The final extract (DZLM) was freeze dried, stored at $-4^{\circ} \mathrm{C} .{ }^{13}$

\section{Preliminary phytochemical investigation}

The obtained extract was utilised for preliminary phytochemical investigation to find the presence of phytochemicals like the amino acids, flavonoids, anthocyanins, glycosides, phenols, proteins, saponins, carbohydrates, mucilage, alkaloids, gums, tannins and steroids by means of biochemical procedures. ${ }^{14}$

\section{Antioxidant activity DPPH method}

The capacity to scavenge, 2-diphenyl-1-picrylhydrazyl (DPPH) free radicals was assessed by the method reported earlier. ${ }^{15}$ The DZLM solutions were prepared in ethanol, to produce $10 \mu \mathrm{g} / \mathrm{mL}$ to $1000 \mu \mathrm{g} / \mathrm{mL}$. The sample $(500 \mu \mathrm{L})$ was added with $2 \mu \mathrm{M}$ DPPH solution $(500 \mu \mathrm{L})$ and kept away from light for $20 \mathrm{~min}$ (room temperature). The absorbance was recorded at $517 \mathrm{~nm}$. Ascorbic acid (AA) was taken the reference standard. The percentage of radical scavenging was obtained from the following formula 1.

$\left[\left(\mathrm{A}_{517 \mathrm{~nm} \text { (control) }}-\mathrm{A}_{517 \mathrm{~nm} \text { (sample) }}\right) / \mathrm{A}_{517 \mathrm{~nm} \text { (control) }}\right] \mathrm{x} 100 \ldots .$. (1) 


\section{ABTS method}

The capacity to scavenge, 2, 2'-azino-bis (3-ethylbenzothiazoline-6-sulphonic acid) $\left[\mathrm{ABTS}^{*+}\right]$ free radical cation was assessed by the standard method. ${ }^{16}$ $7 \mathrm{mM}$ ABTS and $2.45 \mathrm{mM}$ of potassium persulfate was mixed and placed away from light for $12 \mathrm{hr}$. The DZLM concentrations $(10 \mu \mathrm{g} / \mathrm{mL}$ - $1000 \mu \mathrm{g} / \mathrm{mL})$ were prepared using absolute alcohol. They are then mixed with ABTS solution followed by incubation for $30 \mathrm{~min}$. The spectrophotometric readings were noted at $734 \mathrm{~nm}$. The percentage of radical cation scavenging inhibition was analyzed using formula 1. AA has been used as the reference standard.

\section{In vitro antidiabetic activity $\alpha$-amylase inhibition assay}

The $\boldsymbol{\alpha}$-amylase repressing activity was assayed by a reported technique with slight modification. ${ }^{17}$ The sample $(500 \mu \mathrm{L})$ was added with $0.5 \mathrm{mg} / \mathrm{mL}$ of $\alpha$-amylase $(500 \mu \mathrm{L})$ and was incubated at $25^{\circ} \mathrm{C}(10 \mathrm{~min}) .500 \mu \mathrm{L}$ of starch solution has been added then incubated for further $10 \mathrm{~min}$ at $25^{\circ} \mathrm{C} .1 \mathrm{~mL}$ of dinitro salicylic acid reagent was mixed and further reaction was arrested by heating the reaction mixture and then cooling to room temperature. The spectrophotometric readings were noted at $540 \mathrm{~nm}$. Acarbose has been taken as the reference. The percentage of inhibition was obtained by applying the following formula.

$\left[\left(\mathrm{A}_{540 \mathrm{~nm} \text { (control) }}-\mathrm{A}_{540 \mathrm{~nm} \text { (sample) }}\right) / \mathrm{A}_{540 \mathrm{~nm} \text { (control) }}\right] \times 100 \ldots$ (2)

\section{a-glucosidase inhibition assay}

The a-glucosidase repressive activity was measured by a modified assay. ${ }^{18}$ The DZLM $(1 \mathrm{~mL})$ and $2 \% \mathrm{M} / \mathrm{V}$ sucrose $(1 \mathrm{~mL})$ in Tris buffer, $\mathrm{pH} 8$ were incubated at $37^{\circ} \mathrm{C}$ for $5 \mathrm{~min}$. Then, $1 \mathrm{U} / \mathrm{mL}$ a-glucosidase $(1 \mathrm{~mL})$ was added and incubated at $37^{\circ} \mathrm{C}$ for $10 \mathrm{~min}$. and further reaction was blocked by 2 min. boiling of reaction mixture. The glucose quantity has been calculated by the glucose peroxidase method. Acarbose has been used as the reference. The measurement of inhibition was obtained from the formula 2 .

\section{Statistical analysis}

The data were computed as the mean \pm standard error mean (SEM) and conveyed in triplicates $(n=3)$ throughout the experimental procedures. The $\mathrm{IC}_{50}$ values for both antioxidant and antidiabetic studies are calculated by non-linear regression plot among $\%$ of enzyme inhibition ( $\mathrm{x}$-axis) verses concentrations ( $\mathrm{y}$-axis) in antidiabetic assay and among $\%$ of radical inhibition (x-axis) verses concentration (y-axis) in antioxidant assay by means of the GPPS (Graph Pad Prism) Version 5.

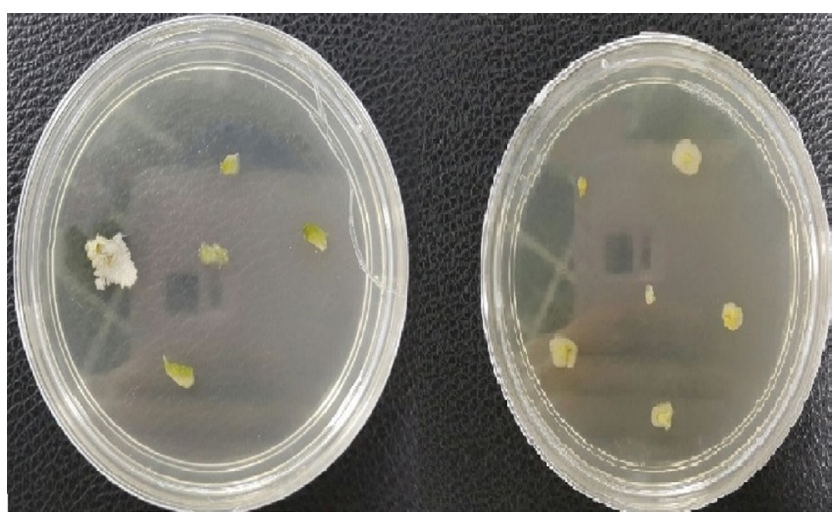

Figure 1: Growth of endophytic bacteria from Durio zibethinus leaves.

\section{RESULTS AND DISCUSSION \\ Bacterial endophyte identification}

The bacterial endophyte was identified using 16S rRNA gene partial sequencing by obtaining its genome sequence data. The growth of endophytic bacteria from Durian leaves is shown in Figure 1. Based upon the hits analysis from mega blast output, the characteristics of the bacteria was revealed by using $16 \mathrm{~S}$ rRNA sequences nucleotide blast analysis. Based on the outcomes, the endophytic bacteria was recognized as Cronobacter sakazakii and the 16S rRNA gene fragments nucleotide sequences were then proposed to GenBank/DDBJ/ EMBL (Accession number: MF615204). ${ }^{19}$ According to, Andrés-Barrao et al. ${ }^{20}$ and Schmid et al. ${ }^{21}$ study results using 16S rRNA phylogenetic analysis of Cronobacter sakazakii, it has been revealed that this endophytic bacteria belonged to the Enterobacteriaceae family.

The rhizosphere has been portrayed as the pool for numerous human pathogens as well as species firmly connected to Cronobacter spp., for instance, Enterobacter cloacae. ${ }^{22}$ It was theorized, that the mechanisms engaged with the interaction between plancoupled bacteria as well their respective host plants are parallel to those accountable for bacteria pathogenicity and this mechanism may likewise be associated with colonising the human body. ${ }^{23,24}$ In the current study, it is demonstrated that members of the Cronobacter genus can be promptly isolated from the host plant roots, that clinical and plant isolates can develop both endophytic and epiphytic colonisation of maize roots as well as tomato and Cronobacter spp. capable of producing factors conceivably gainful to plant growth. This is evident for the plant as a fundamental natural habitat of Cronobacter spp. ${ }^{20}$

As reported by Johler et al. ${ }^{25}$ that the pigment carotenogenic nature of Cronobacter strain ES5 was found in both chemical as well as the molecular 
level. Carotenoids are perceived to balance the cellular membranes in addition to impact the membrane fluidity. Thus, executing antioxidants property, it might be able to scavenge reactive oxygen species. ${ }^{26}$

The partial genome sequence of DZLM was found to be $769 \mathrm{bp}$ as follows

GGGGTGGGGGGCTACACATGCAGTCGACGG TAACAGGGAGCAGCTTGCTGCTCTGCTGACG AGTGGCGGACGGGTGAGTAATGTCTGGGAA ACTGCCTGATGGAGGGGGATAACTACTGGAA ACGGTAGCTAATACCGCATAACGTCTACGGAC CAAAGTGGGGGACCTTCGGGCCTCATGCCAT CAGATGTGCCCAGATGGGATTAGCTAGTAGG TGGGGTAACGGCTCACCTAGGCGACGATCCC TAGCTGGTCTGAGAGGATGACCAGCCACACT GGAACTGAGACACGGTCCAGATCCTACGGGA GGCAGCAGTGGGGAATATTGCACAATGGGCG CAAGCCTGATGCAGCCATGCCGCGTGTATGA AGAAGGCCTTCGGGT'TGTAAAGTACT'TTCAG
CGGGGAGGAAGGTGTTGTGGTTAATAACCAC AGCAATTGACGTTACCCGCAGAAGAAGCACC GGCTAACTCCGTGCCAGCAGCCGCGGTAATA CGGAGGGTGCAAGCGTTAATCGGAATTACTG GGCGTAAAGCGCACGCAGGCGGTTGATTAAG TCAGATGTGAAATCCCCGGGCTCAACCTGGG AACTGCATTTGAAACTGGTCAGCTTGAGTCT CGTAGAGGGGGGTAGAATTCCAGGTGTAGCG GTGAAATGCGTAGAGATCTGGAGGAATACCG GTGGCGAAGGCGGCCCCCTGGACGAAGACTG ACGCTCAGGTGCGAAAGCGTGGGGAGCAAAC AGGATTAGATACCTGGGTAGTCCAA

\section{Preliminary phytochemical analysis}

The preliminary qualitative phytochemical analysis of DZLM revealed the occurrence of several phytoconstituents: alkaloids, phenols, flavonoids, glycosides, steroids, mucilage, carbohydrates, and the constituents like flavonoids, polyphenols, alkaloids are the known to have antioxidant properties as studied in various researches. ${ }^{27,28}$
(A)

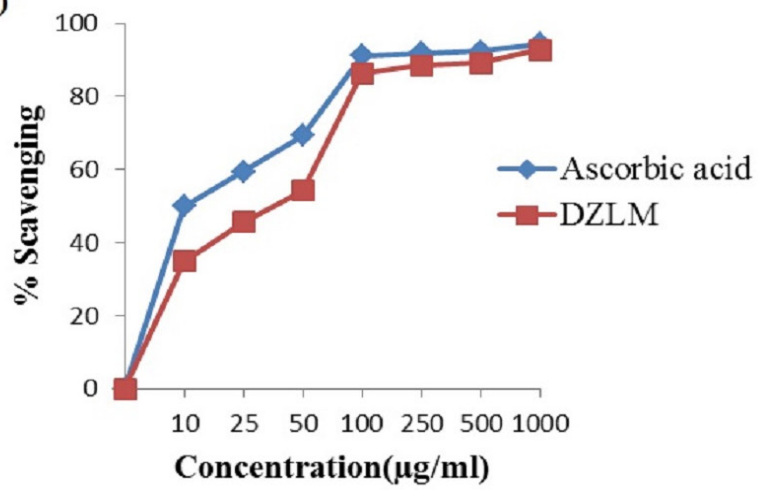

(B)

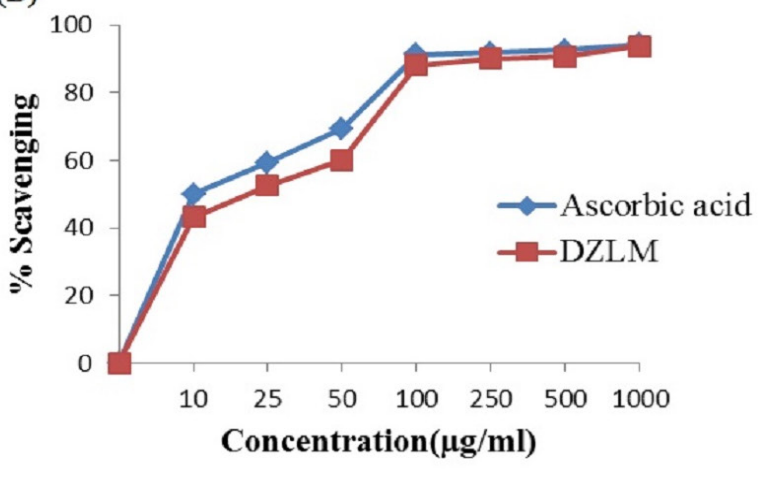

Figure 2: Radical scavenging potential of DZLM and Ascorbic acid using (A) DPPH assay (B) ABTS assay methods.

Table 1: Percentage $\alpha$-amylase and $\alpha$-glucosidase inhibition of DZLM and Acarbose.

\begin{tabular}{|c|c|c|c|c|}
\hline \multirow{2}{*}{ Concentration $(\mu \mathrm{g} / \mathrm{mL})$} & \multicolumn{4}{|c|}{$\%$ Inhibition (mean \pm SEM) } \\
\cline { 2 - 5 } & \multicolumn{2}{|c|}{ Alpha amylase } & Acarbose & Alpha glucosidase \\
\cline { 2 - 5 } & DZLM & $39.4 \pm 1.75$ & $36.8 \pm 0.46$ & $40 \pm 0.27$ \\
\hline 100 & $21.2 \pm 1.01$ & $57.6 \pm 1.75$ & $48.8 \pm 1.22$ & $52 \pm 0.46$ \\
\hline 200 & $51.5 \pm 1.75$ & $64.6 \pm 1.01$ & $66.4 \pm 0.27$ & $68.8 \pm 0.53$ \\
\hline 400 & $63.7 \pm 1.01$ & $69.7 \pm 1.01$ & $82.4 \pm 0.53$ & $80.8 \pm 0.71$ \\
\hline 1000 & $66.7 \pm 1.01$ & $93.9 \pm 1.01$ & $89.6 \pm 0.27$ & $90.4 \pm 0.46$ \\
\hline
\end{tabular}




\section{In vitro antioxidant assay}

The crude fraction of endophyte was subjected to in vitro antioxidant assay and the results of $\mathrm{DPPH}$ and ABTS assay were depicted in Figure 2A and $2 \mathrm{~B}$ respectively. At $1000 \mu \mathrm{g} / \mathrm{mL}$, DZLM showed 91.43\% $\left(\mathrm{IC}_{50} \pm\right.$ SEM: $\left.161 \pm 0.07 \mu \mathrm{g} / \mathrm{mL}\right)$ and $93.8 \%\left(\mathrm{IC}_{50} \pm \mathrm{SEM}\right.$ : $126 \pm 0.09 \mu \mathrm{g} / \mathrm{mL}$ ) inhibition of free radicals of DPPH and ABTS, respectively. Comparably, in above assays AA exhibited $94.38 \%\left(\mathrm{IC}_{50} \pm\right.$ SEM: $137 \pm 0.09 \mu \mathrm{g} / \mathrm{mL}$ ) and $96.7 \% \quad\left(\mathrm{IC}_{50} \pm \mathrm{SEM}: 107 \pm 0.09 \mu \mathrm{g} / \mathrm{mL}\right)$. In the past studies, phytoconstituents, for instance, steroids, flavonoids, phenols, and alkaloids are proven to have antioxidant properties to scavenge the free radicals. ${ }^{29}$

\section{In vitro antidiabetic activity}

DZLM was tested for in vitro antidiabetic activity by inhibition assay of $\boldsymbol{\alpha}$-amylase and $\boldsymbol{\alpha}$-glucosidase. Table 1 displayed the inhibitory effect DZLM and acarbose against $\boldsymbol{\alpha}$-amylase and $\boldsymbol{\alpha}$-glucosidase enzymes. At $1000 \mu \mathrm{g} / \mathrm{mL}$, DZLM exhibited good $\boldsymbol{\alpha}$-amylase and $\boldsymbol{\alpha}$-glucosidase enzyme inhibition with $90.9 \%$ $\left(\mathrm{IC}_{50} \pm\right.$ SEM: $\left.239 \pm 0.08 \mu \mathrm{g} / \mathrm{mL}\right)$ and $89.6 \%\left(\mathrm{IC}_{50} \pm \mathrm{SEM}\right.$ : $241 \pm 0.08 \mu \mathrm{g} / \mathrm{mL})$ respectively. Likewise, in the above assays, acarbose showed $93.9 \%\left(\mathrm{IC}_{50} \pm\right.$ SEM: $225 \pm 0.15$ $\mu \mathrm{g} / \mathrm{mL}$ ) and $90.4 \%\left(\mathrm{IC}_{50} \pm\right.$ SEM: $\left.222 \pm 0.04 \mu \mathrm{g} / \mathrm{mL}\right)$.

Both $\alpha$-amylase and $\alpha$-glucosidase enzymes are vital to digest carbohydrates and incline the blood glucose level. Thus, the inhibition of these enzymes was concerned for the treatment of diabetes mellitus..$^{30,31}$

\section{CONCLUSION}

It is revealed from the present study, the presence of biologically active constituents within the bacterial endophytic extract exhibited good antioxidant and antidiabetic properties. It merits stating that the leaves of Durio zibethinus which shelter the endosymbiont, Cronobacter sakazakii have been utilized in folklore medicine. Endophytes within these plants hold extraordinary potential in producing bioactive compounds. Additional research on bacterial endophytic crude extract like purification and fractionation and their structure elucidation will uncover the obscure compounds in the isolates and helps in the development of the future.

\section{ACKNOWLEDGEMENT}

The researcher would like to thank the Deanship of Scientific Research, Qassim University for funding publication of this project.

\section{CONFLICT OF INTEREST}

The authors declare that there is no conflict of interest.

\section{ABBREVIATIONS}

Cm: Centimeter; $\mu$ g: Microgram; \%: Percent; $\lambda_{\max }$ : Wavelength of maximum absorbance; IC $_{50:}$ Inhibitory concentration $50 \%{ }^{\circ} \mathrm{C}$ : Degree celcious; hr: Hour; Mg: Milligram; Rpm: Revolutions per minute; $\mathrm{mL}$ : Milliliter; $\mu \mathrm{L}$ : Microliter; Min: Minute; SEM: Standard error mean; UV: Ultraviolet.

\section{REFERENCES}

1. Rajagopal K, Sundharamoorthy M, Arumugam P, Basha JW, Govindarajan K, et al. In vitro antibacterial activity of endophytic fungal extracts isolated from a pharmaceutically important plant Ficus religiosa L. Int J Pharma Bio Sci. 2015;6:1093-8.

2. Grover JK, Yadav S, Vats V. Medicinal plants of India with anti-diabetic potential. J Ethnopharmacol. 2002;81(1):81-100.

3. Tan RX, Zou WX. Endophytes: A rich source of functional metabolites. Nat Prod Rep. 2001;18(4):448-59.

4. Krentz AJ, Bailey CJ. Oral antidiabetic agents. Drugs. 2005;65(3):385-411.

5. Kasiviswanath R, Ramesh A, Kumar KE. Hypoglycemic and antihyperglycemic effect of Gmelina asiatica Linn. In normal and in alloxan induced diabetic rats. Biol Pharm Bull. 2005;28(4):729-32.

6. Strain JJ. Disturbances of micronutrient and antioxidant status in diabetes. Proc Nutr Soc. 1991;50(3):591-604.

7. Armstrong AM, Chestnutt JE, Gormley MJ, Young IS. The effect of dietary treatment on lipid peroxidation and antioxidant status in newly diagnosed noninsulin dependent diabetes. Free Radic Biol Med. 1996;21(5):719-26.

8. Brownlee M. Biochemistry and molecular cell biology of diabetic complications. Nature. 2001;414(6865):813-20.

9. Gorinstein S, Poovarodom S, Leontowicz H, Leontowicz M, Namiesnik J, et al. Antioxidant properties and bioactive constituents of some rare exotic Thai fruits and comparison with conventional fruits: In vitro and in vivo studies. Food Res Int. 2011;44(7):2222-32.

10. Haruenkit R, Poovarodom S, Vearasilp S, Namiesnik J, Sliwka-Kaszynska M, et al. Comparison of bioactive compounds, antioxidant and antiproliferative activities of Mon Thong durian during ripening. Food Chem. 2010;118(3):5407.

11. Sadrati N, Daoud H, Zerroug A, Dahamna S, Bouharati S. Screening of antimicrobial and antioxidant secondary metabolites from endophytic fungi isolated from wheat (Triticum durum). J Plant Prot Res. 2013;53(2):128-36.

12. Chigurupati S, Marri MR, Kumar A, Nemala AR, Nanda SS, et al. Bacterial Endo-Symbiont Inhabiting Durio zibethinus leaves and their Antibacterial Potential. Int J Pharmtech Res. 2018;11(3):198-205.

13. Ramasamy K, Lim SM, Bakar AH, Ismail N, Ismail MS, et al. Antimicrobial and cytotoxic activities of Malaysian endophytes. Phytother Res. 2010;24(5):6403.

14. Chigurupati S, Mohammad JI, Vijayabalan S, Vaipuri ND, Selvarajan KK, et al. Quantitative estimation and antimicrobial potential of ethanol extract of Durio zibethinus Murr. Leaves. Asian J Pharm Clin Res. 2017;10(9):251-4.

15. Salar U, Khan KM, Chigurupati S, Syed S, Vijayabalan S, et al. New Hybrid Scaffolds based on Hydrazinyl Thiazole Substituted Coumarin; As Novel Leads of Dual Potential; In vitro a-Amylase Inhibitory and Antioxidant (DPPH and ABTS Radical Scavenging) Activities. Med Chem. 2019;15(1):87-101.

16. Chigurupati S, Selvaraj M, Mani V, Selvarajan KK, Mohammad JI, et al. Identification of novel acetylcholinesterase inhibitors: Indolopyrazoline derivatives and molecular docking studie. Bioorg Chem. 2016;67:9-17.

17. Khan M, Alam A, Khan KM, Salar U, Chigurupati S, et al. Flurbiprofen derivatives as novel a-amylase inhibitors: Biology-oriented drug synthesis (BIODS), in vitro and in silico evaluation. Bioorg Chem. 2018;81:157-67. 
18. Hu X, Cheng D, Wang L, Li S, Wang Y, et al. Evaluation of anti-hyperglycemic effect of Actinidia kolomikta (Maxim. etRur.) Maxim. Root extract, Pak J Pharm Sci. 2015;28(3 Suppl):1135-40.

19. Chigurupati S, Mohammad JI, Selvarajan KK, Vijayabalan S, Thanasegaran SA, et al. Cronobacter sakazakii strain AIMST. DzLe1 16S ribosomal RNA gene, partial cds, GenBank, Accession Number: MF615204. 2017. https:// www.ncbi.nlm.nih.gov/popset/1229086025? report=genbank

20. Andrés-Barrao C, Lafi FF, Alam I, Zélicourt DA, Eida AA, et al. Complete Genome Sequence Analysis of Enterobacter sp. SA187, a Plant Multi-Stress Tolerance Promoting Endophytic Bacterium. Front Microbiol. 2017;8:2023.

21. Schmid M, Iversen C, Gontia I, Stephan R, Hofmann A, et al. Evidence for a plant-associated natural habitat for Cronobacter spp., Res Microbiol. 2009;160(8):608-14.

22. Berg G, Eberl L, Hartmann A. The rhizosphere as a reservoir for opportunistic human pathogenic bacteria. Environ Microbiol. 2005;7(11):1673-85.

23. Cao H, Baldini RL, Rahme LG. Common mechanisms for pathogens of plants and animals. Annu Rev Phytopathol. 2001;39(1):259-84.

24. Rahme LG, Stevens EJ, Wolfort SF, Shao J, Tompkins RG, et al. Common virulence factors for bacterial pathogenicity in plants and animals. Science. 1995; 268(5219):1899-902.
25. Johler S, Stephan R, Hartmann I, Kuehner KA, Lehner A. Genes involved in yellow pigmentation of Cronobacter sakazakii ES5 and influence of pigmentation on persistence and growth under environmental stress. Appl Environ Microbiol. 2010;76(4):1053-61.

26. Ziegelhoffer EC and Donohue TJ. Bacterial responses to photo-oxidative stress. Nat Rev Microbiol. 2009;7(12):856-63.

27. Middleton EJ, Kandaswami C, Theoharides TC. The effects of plant flavonoids on mammalian cells: Implications for inflammation, heart disease and cancer. Pharmacol Rev. 2000;52(4):673-751.

28. Pietta PG. Flavonoids as antioxidants. J Nat Prod. 2000;63(7):1035-42.

29. Sahoo S, Ghosh G, Das D, Nayak S. Phytochemical investigation and in vitro antioxidant activity of an indigenous medicinal plant Alpinia nigra B.L. Burtt. Asian Pac J Trop Biomed. 2013;3(11):871-6.

30. Noreen T, Taha M, Imran S, Chigurupati S, Rahim F, et al. Synthesis of alpha amylase inhibitors based on privileged indole scaffold. Bioorg Chem. 2017;72:248-55

31. Taha M, Irshad M, Imran S, Rahim F, Selvaraj M, et al. Thiazole Based Carbohydrazide derivatives as $\alpha$-Amylase inhibitor and their molecular docking study. Heteroatom Chem. 2019;2019:8s.

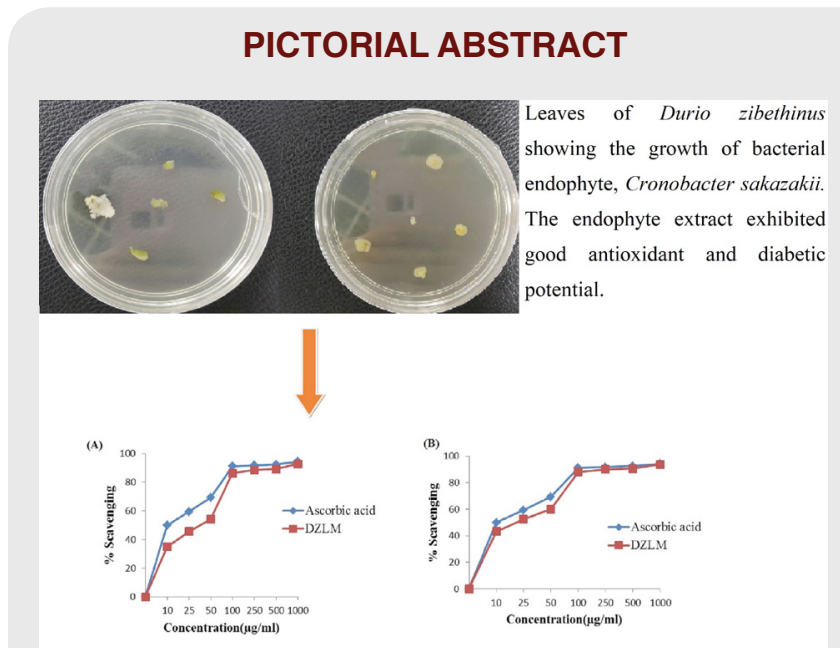

\section{SUMMARY}

Natural compounds and their associated moieties have traditionally been incredible as a resource of therapeutic agents. Endophytes are microorganisms, that inhabit within healthy plant tissues through having a symbiotic relationship. They are not only are useful for plants but also are of profitable importance to humans. They serve as medicines, or the compounds of high significance in research. The endophytic bacteria residing in leaves of Durio zibethinus is isolated and identified as Cronobacter sakazakii using 16s rRNA partial genome sequencing. After performing preliminary qualitative analysis, the crude extract of the endophyte shown the presence of phytoconstituents like alkaloids, phenols, flavonoids, glycosides, steroids, mucilage and carbohydrates and the presence of active phytoconstituents might be responsible for its good antioxidant and antidiabetic potentials.

\section{About Authors}

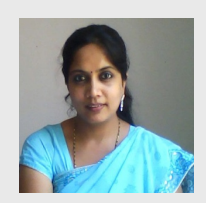

Dr. Sridevi Chigurupati has delivered her research ideas in the form of talks as guest lecture and keynote speaker at various National and International Conferences and Universities in Virginia, Las Vegas, California, India, Thailand, Malaysia, and Dubai. She has published more than 90 articles in reputed journals with good impact along with few book chapters. She has been serving as a reviewer and editorial board member for many reputed high-quality journals. She received many auspicious awards from India, Malaysia, Saudi Arabia for her research and teaching. She has achieved patent for new chemical entities on neurological disorder.

She is also a lifetime member for many government organizations like American Chemical Society (U.S.A); Asia-Pacific Chemical, Biological \& Environmental Engineering Society (China); Malaysian Scientific Association (Malaysia) and Fellow of Institution of Chemists (India), Pharma Medical Sciences Development Society (India).

Cite this article: Chigurupati S, Vijayabalan S, Palanimuthu VR, Das S, Bhatia S. Bacterial Endophyte Inhabiting Durio zibethinus and its Radical Scavenging and Antidiabetic Potential. Indian $\mathrm{J}$ of Pharmaceutical Education and Research. 2021;55(3):857-62. 